\title{
APPLICATION POSSIBILITIES OF MIND MAP IN SOCIAL SKILLS TRAINING OF CHILDREN WITH BEHAVIOURAL PROBLEMS
}

\section{Kirilova-Moutafova*}

\author{
Department of Social Activities, Faculty of Medicine, Trakia University, Stara Zagora, Bulgaria
}

\begin{abstract}
What impresses in clinical practice when dealing with children with antisocial destructive behaviours are the difficulties they have to foresee the impact of their own actions; and with some children, to such an extent that it is even impossible to track their behaviour in the time to come. This is a significant aspect and a goal of the training of children with behavioural issues: developing skills for action planning; foreseeing the outcome in the future and making the right choices, especially in conflict situation. Training by using mind map techniques in this study is based on an objective assessment of the real needs of a child and the goal of the training is to translate the acquired social skills into real-life situations. This study provides the results of twelve months of monitoring of runaways from Correctional Boarding Schools (CBS) and Social-Educational Boarding Schools (SEBS) of 50 children trained by using the mind map technique.
\end{abstract}

Key words: antisocial behaviour, social education, runaway

\section{INTRODUCTION}

The term 'mind mapping' was coined by Tony Buzan in the 1960s; still, using diagrams in the form of 'maps' of information presented by means of branching and radiating, have been used for centuries now. It was Aristotle, for instance, who in his day graphically conceptualized categories (1). Traditional perception in reading is left-to-right/top-tobottom oriented, while tree diagrams with a key word and radiating branching sets of lines allow taking in, comprehending and memorizing an image in its entirety. Generally speaking, this manner of structuring information is conducive to digesting the information more easily, to establishing connections and generating ideas. The efficacy of the interaction of the neural circuitry between the two hemispheres is believed to increase significantly and this technique is now used in brainstorming, mnemonic training, for improving learning effectiveness, in problemsolving and decision-making trainings, structuring of information, suggestology, etc. The laws of mind mapping were originally devised by Tony Buzan as follows: 1. Making a central image that

\footnotetext{
*Correspondence to: Iliyana Kirilova-Moutafova, Trakia University, Faculty of Medicine, Department of Social Activities, 11 "Armeiska" street, 6000, Stara Zagora, Bulgaria, telephone: 042 644-417,e-mail: ilianskk@abv.bg
}

represents the subject using at least three colours; 2. Using images, symbols and codes in various sizes throughout the map; 3 . Introducing key words; 4 . Each word or image is on its own and each word or picture sits on its own line; 5. Lines should be connected, starting from the central image; lines should be thicker at the centre and thinner further out; 6 . Using many colours throughout the mind map for visual stimulation as well as for codifying and grouping; 7. Importantly, a mind map should have a highlight and open up associations (2). According to a study by Farrand, Hussain and Hennessy (2002), mind mapping improved significantly the long-term memory of factual recall in their participants by $10 \%$ in a study conducted among high school students who were exposed to a 600word passage compared to a $6 \%$ increase for those using preferred memory techniques. The authors conducted a study to conclude that the mind map technique helped $80 \%$ of the students to make sense of concepts and ideas in various areas. The meta-analysis concludes that the mind map technique is more efficacious both in terms of remembering and effect compared to reading a text, attending a lecture or participating in discussions and significantly more efficacious with children of lesser abilities compared to children with higher intelligence and achievements (3). 
Many of the children at the specialised institutions - Correctional Boarding School (CBS) and Social-Educational Boarding Schools (SEBS) and crisis centres-have behavioural problems. Placement in an institution is not an efficient measure in itself to cope with children's antisocial behaviours and more often than not ends up in running away from the institution. Running away is a situation putting child's health at risk and is a potential risk to the society. Frequently, the runaways are subjected to an offence or they themselves commit a new offence (damaging property, theft, aggressive actions against other persons, robberies). Precipitating factors, preceding a running away from the institution are accumulated dissatisfaction with the lack of contacts with the child's nearest and dearest and understimulating social environment. An immediately preceding event can be said to be a releasing mechanism, which event has been subjectively experienced and assessed as negative (an imposed punishment or ban, or a violent act committed by another child at the institution) or more often than not finding money or psychoactive substances such as alcohol and soft drugs is the motive behind the running away.

\section{STUDY}

It was not a random choice to provide training in conditions following detainment by the police and placement at Shelters for Temporary Accommodation of Minors and Under-aged. Running away is a particular situation directly relating to children with behavioural problems and is objectively measurable. It is an easy choice for a child to opt for a problematic behaviour in view of the direct correlation: behaviour - running away consequences - detainment. In children's mind, such a situation is associated with a punishment. They are offered instead to take part in a study and training supposed to teach them foresee the negative results of their own actions and expectedly, to leave a memory trace (engram) in a similar situation in the future. Such an emotionally charged situation, where children are offered alternative thinking, can be compared with a crisis intervention when a child is more open to realise and make sense of what happens. All this is just a step towards the ultimate goal: achieving a decrease in status offences and juvenile delinquency.

Prior to the training, the information from available relevant sources about each child was analysed: social papers, medical documentation, reports on social functioning, the information by Inspectors Juvenile Pedagogic Police Department Rooms (JPPD), Ministry of Interior, observations of the staff, the data of the test methods and of the focused (semi-structured) interview. The summary of each of the cases was intended for an analysis of how the child's vulnerability, feelings and environmental stressors work together and bear upon the child's behaviours.

Within the study, 50 kids with behavioural deviations, placed in the Shelter for Temporary Accommodation of Minors and Under-aged, Sofia Directorate Ministry of Interior after being detained by the police for running away from a specialized institution, were trained using the mind map technique. The training can be presented as follows: The formulated problem -in this particular case the topic was 'running away'-was written in the centre of an A4 paper sheet being a central image. The major branches were identified by the right words or phrases to describe the major lines. Symbols were added whenever possible. Different colours were used for each of the branches. Additional branches were also identified. Branches were added until it was assumed that the respective line has been described. Then the whole picture was considered as one piece. Running away was the central image. The questions and the relevant main lines were WHO, WHY, WHAT and HOW. All possible versions and solutions related to prevention of running away and generated by the particular child alone stood as a counterpoint to the central topic.

WHO is the one at the CBS, SEBS or the crisis centre they have been sent to, with whom they are in a closer and trust-based contact and whom they'd approach for advice or help especially in a situation of a compulsion or consideration to run away from the institution; WHY shouldn't he or she run away: all the negative implications of this situationimmediate or later risks and consequences, worsening the present-wanted and detained by the police, being imposed penalty for their deed, and often, being moved to another type of institution, i.e. worsening of the situation.

WHAT they want to achieve for themselves: short-term and long-term goals. What alternatives the child would resort to in this situation and would such an alternative prove helpful in attaining the goals.

HOW to overcome negative emotions leading to the decision (desire, consideration) to run away rather than act out; how she or he coped with and what has helped him/her in similar situations.

Problem solving training using the mind map technique is a relatively unspecific technique, which is strongly structured. In the course of the training all techniques and principles known for 
fostering effective learning were used. Specific techniques were applied such as instruction, monitoring, role-playing, and feedback. The training courses focused generally on the communicative skills and particularly, on the aspects of nonverbal communication and improvement of children's ability to perceive and react to social signs since a number of children with behavioural problems have difficulties to communicate with the others, because they fail to notice and interpret the massages conveyed by the other people. The approach focused on the distorted comprehension of social events demonstrated by children with externalised behavioural problems as well as towards improving their ability to regulate their own emotional response. These children received very little positive feedback for their efforts in the past and giving them positive feedback, taking into account their strong points, had a strongly motivational effect. Constructive feedback was also vital: which can be improved. Learning and changing is impossible without feedback and instructions.
The duration of the training using the mind map technique was of 50 to 60 minutes. Each of the kids received the mind maps they themselves have worked out. An agreement was signed with each of them on not running away, which was a key aspect of the training. The generalization was rendered in a 6-month monitoring of each of the children.

\section{RESULTS AND DISCUSSION}

The assumption that teaching social skills using the mind map technique has a positive effect upon the rate of the runaways from specialized institutions and that these are decreasing, was tested on the basis of comparing the rates of running away in two groups of participants (the group that has been trained and the one that had not been trained prior to and after the study). Ttests were conducted for the purpose with one sample tested twice (repeated measures) (Pairedsamples T-Test). The number of running away was measured in the periods of six months prior to and after the study and the training. The results of the two T-tests are given in Tables 1 and 2 below:

Table 1. Running away rates in the periods of six months prior to and after conducting the study on the group that has been trained

\begin{tabular}{|l|l|l|l|l|}
\hline \multirow{2}{*}{$\begin{array}{l}\text { Period before/after the } \\
\text { study }\end{array}$} & Number of runaways & \multirow{2}{*}{ t } & \multirow{2}{*}{ Sig. } \\
\cline { 2 - 5 } & Average & S.d. & \multirow{2}{*}{5.25} & \multirow{2}{*}{$.000^{*}$} \\
\hline Six months prior & 1.86 & 0.67 & & \\
\hline Six months after & 1.38 & 0.95 & \\
\hline
\end{tabular}

$\mathrm{N}=50 ; * \mathrm{p} \leq .001$

Table 2. Running away rates in the periods of six months prior to and after conducting the study on the group that has not been trained

\begin{tabular}{|l|l|l|l|l|}
\hline \multirow{2}{*}{$\begin{array}{l}\text { Period before/after the } \\
\text { study }\end{array}$} & \multicolumn{2}{|l|}{ Number of runaways } & \multirow{2}{*}{ t } & \multirow{2}{*}{ Sig. } \\
\cline { 2 - 4 } & Average & S.d. & \multirow{2}{*}{1.19} & $.24 *$ \\
\hline Six months prior & 1.82 & 0.75 & & .24 \\
\hline Six months after & 1.68 & 0.82 & & \\
\hline
\end{tabular}

$\mathrm{N}=50$; The difference is statistically insignificant;

The tables above show that the group of children that have been trained have a statistically significant difference $(\mathrm{p} \leq .001)$ between the running away rate in the period of six months prior to and that after the study was conducted with the average rate in the latter period being fairly lower compared to that of the former. As with those who have not been trained, the difference between the running away rate prior to and that after the study was conducted is statistically insignificant. Expectedly, with them no effect whatsoever was recorded prior to and after the study was conducted. This comes to confirm the expectation that training social skill using the mind map technique has a positive effect on the frequency of negative behaviours of children after the training.

\section{CONCLUSION}

The method based on using the mind map techniques is practically easily applicable and pragmatic requiring not engaging in a particular paradigm or therapeutic theory. It seems to provide a child with the opportunity to receive efficacious interventions and hopefully obtain something tangible and resultative.

\section{REFERENCES}

1. Buzan, T., (2000). Use Your Head BBC Consumer Publishing, ISBN 0-563-53729-9

2. Farrand P, Hussain F, Hennessy E. (2002) The efficacy of the 'mind map' study technique Med Educ. 36(5):426-31

3. Buzan T., (2003) The Mind Map Book: Radiant Thinking- Major Evolution in Human Thought; BBC Active ISBN 0-56348701-1 